\title{
The effect of sodium percarbonate dose on the reduction of organic compounds in landfill leachate
}

\author{
Joanna Muszyńska ${ }^{1 *}$, Jarosław Gawdzik ${ }^{1}$, and Mikołaj Sikorski² \\ ${ }^{1}$ Kielce University of Technology, Faculty of the Environmental Engineering, Geomatics and Energy, al. Tysiąclecia Państwa Polskiego \\ 7, 25-314 Kielce, Poland \\ ${ }^{2}$ Warsaw University of Technology Branch in Plock, Faculty of Civil Engineering, Mechanics and Petrochemistry, ul. Łukasiewicza 17, \\ 09-400 Płock, Poland
}

\begin{abstract}
The paper discusses the issue of using classic Fenton's reagent modification for pre-treatment of leachate from a landfill in Janczyce (Świętokrzyskie Voivodeship, Poland) - sodium percarbonate $\left(2 \mathrm{Na}_{2} \mathrm{CO}_{3} \cdot 3 \mathrm{H}_{2} \mathrm{O}_{2}\right)$ was used as an alternative source of hydrogen peroxide, and hydrated iron sulphate ((II) $\mathrm{FeSO}_{4} \cdot 7 \mathrm{H}_{2} \mathrm{O}$ ) was the source of iron ions. The tests were carried out at initial process $\mathrm{pH}=3$, for different doses of the $\mathrm{Fe}^{2+}$ catalyst (ranging within $100 \div 5400 \mathrm{mgFe} / \mathrm{L}$ ), and for mass ratio iron (II) to sodium percarbonate $-1: 3$. Three doses were selected after this stage, for which the following parameters were examined: the effect of initial process $\mathrm{pH}$ ranging between 2 and 4 , the effect of oxidation process duration $\left(30 \div 150 \mathrm{~min}\right.$.), and the effect of the ratio $\mathrm{Fe}^{2+}$ to sodium percarbonate $(1: 3,1: 5$ and $1: 7)$. The values of selected parameters ( $\mathrm{pH}, \mathrm{COD}, \mathrm{TOC})$ in leachates, both before and after the treatment process have been determined according to applicable standards. Completed tests have proven, inter alia, that the proposed implementation of the Fenton's method with sodium percarbonate may be an effective alternative for hydrogen peroxide as an oxidiser; with an increasing dose of the $2 \mathrm{Na}_{2} \mathrm{CO}_{3} 3 \mathrm{H}_{2} \mathrm{O}_{2}$, the improvement in landfill leachate remediation efficiency measured by decreasing TOC and COD values reaches certain extent only; the process modified with sodium percarbonate may be effective already at $\mathrm{pH}=4$.
\end{abstract}

\section{Introduction}

Waste production is an inevitable consequence of the functioning of a society; therefore it is important to reduce the volume and rational management of already generated wastes. The following should be listed among waste management methods: reuse, combustion, composting, and landfilling. Unfortunately, in spite of hazards it involves, waste landfilling in many countries is still the most commonly used disposal method [1-3]. Landfill shall be treated as a bioreactor, in which a number of biochemical and microbiological processes take place. As a result of landfill functioning, pollution emissions are generated, which may pose hazard to environment, e.g. biogas or leachates [4-6]. Landfill leachates consist not only of rainwater flowing through landfill pit, but also of all substances and ingredients washed out from wastes, and products of biochemical reactions taking place in wastes kept in a landfill. They are generated not only while landfill is in service, but also after its closing, during its reclamation. It is estimated that in European climatic conditions approximately $3.5 \div 8.5 \mathrm{~m}^{3}$ of leachates are generated from 1 ha of landfill, however, in case of heavy rainfall this volume may increase even by $200 \%$ [2,3,7-11].

Leachate constitution reflects processes occurring in a landfill pit and changes throughout the facility service period, but it also depends on many factors, e.g. the volume, type and fragmentation of wastes, climate, geometrical parameters of a landfill, and compaction degree $[2,12,13]$. The following should be listed among the main leachate ingredients [2]: dissolved organic compounds (given as $\mathrm{COD}, \mathrm{BOD}_{5}, \mathrm{TOC}, \mathrm{VFAs}$ ) and more complex humus compounds, inorganic macroelements (i.a. $\mathrm{Ca}, \mathrm{Mg}, \mathrm{Mn}, \mathrm{Fe}, \mathrm{SO}_{4}{ }^{2-}$ ), heavy metals and xenobiotic substances. In addition, more than two hundred substances have been distinguished in leachates, which constitute organic impurities, and approximately thirty five of them are particularly dangerous substances [10,14]. Highly concentrated landfill leachates generated in this way require specialist treatment. While choosing treatment technology, the following should be taken into account, among other things: changing chemical constitution of leachate, its volume and capital intensity of the method.

Biological methods are recommended in particular for treating leachates from new landfills, but due to high volumes of nitrogen compounds and disadvantageous proportion relative to organic carbon, treatment of leachates using this method is difficult. In case of leachates from stabilised landfills, physicochemical methods are recommended, i.a. membrane processes, coagulation, adsorption on active carbon, distillation or combustion. Frequently, combinations of different

* Corresponding author: jdlugosz@tu.kielce.pl 
methods are also used to treat leachates [3,9,11]. More and more often, the AOP (Advanced Oxidation Processes) become an alternative for conventional treatment methods. I.a., the following are used in oxidation processes to generate ${ }^{\circ} \mathrm{OH}$ radicals: hydrogen peroxide (most often in form of a $30 \%$ solution), UV radiation, $\gamma$ radiation, ozone and ultrasounds. Moreover, catalyst additives are used, e.g. $\mathrm{TiO}_{3}, \mathrm{Mn}^{2+}, \mathrm{Fe}^{2+}$. Hydroxyl radical has highest oxidising potential among all oxidisers $(2.80 \mathrm{~V})$, and thus it is characterised by good reactivity and high reduction efficiency in relation to complex organic compounds $[9,10,15]$. Fenton's process efficiency is affected by $\mathrm{pH}$ (optimum range $2.5 \div 4$ ), the $\mathrm{Fe}^{2+}$ to $\mathrm{H}_{2} \mathrm{O}_{2}$ ratio, and $\mathrm{Fe}^{2+}$ dose. Moreover, it is recommended to keep process temperature range within $20 \div 40^{\circ} \mathrm{C}$. Depending on the above-mentioned factors, reaction time varies from several minutes to few hours [16].

The course of conventional Fenton's reaction can be shown in general form as [17]:

$$
\mathrm{Fe}^{2+}+\mathrm{H}_{2} \mathrm{O}_{2} \rightarrow \mathrm{Fe}^{3+}+\mathrm{OH}^{-}+\cdot \mathrm{OH}
$$

Besides high efficiency, Fenton's process advantages include relatively low process execution costs compared to other AOP processes. Additionally, this method does not require using any specialised equipment, e.g. UV lamp or ozone generators. Apart from this, no harmful products are generated during oxidation process (compared to chlorination or ozonisation) [17, 18]. Aside from conventional Fenton's method, its modifications are used as well, e.g. photo-Fenton (using UV rays), radiation Fenton (using radiation), electro-Fenton, and other. However, it is noteworthy that in vast majority, the tests concerning Fenton's reagent were carried out for selectively chosen contaminants, not actual effluent. Considering this, Fenton's reaction is relatively rarely used on a technical scale to treat liquid industrial wastes, including landfill leachates [17].

The aim of the study was to develop an effective modification of the Fenton process with the use of sodium percarbonate for pre-treatment of landfill leachate.

\section{The scope and methodology of tests}

The tests have been performed using leachates from a landfill located in Janczyce (Świętokrzyskie Voivodeship, Baćkowice Borough), which is a part of Municipal Waste Treatment Plant in Janczyce and is in service since 2003. The Plant provides its services for approximately 150,000 residents, and besides landfill sectors it is provided with mechanical waste processing system and a composting plant. The landfill (3.64 ha) is filled with deposits of refuse after mechanical processing of mixed municipal wastes, refuse left after sorting, and other wastes, which cannot be recovered.

Leachate sampling, storage and chemical constitution analysis have been carried out according to applicable standards: PN-ISO 5667-10:1997 [19]. The following parameters have been determined in leachate samples before and after treatment process, according to applicable standards:

- chemical oxygen demand (COD) has been determined using photometric method (Spectroquant) - determination by cuvette tests in the Spectroquant Nova 60 spectrophotometer from MERCK after preheating in the TR 320 thermoreactor from MERCK $(120 \mathrm{~min}$. at the temp. $148^{\circ} \mathrm{C}$ ); quantification level depending on the method: $10 \div 10000 \mathrm{mg} / \mathrm{L}$,

- total organic carbon (TOC) has been determined using the UV oxidation method with per-disulphate in the StarTOC System apparatus, according to the PN-EN 1484:1999 [20]; quantification level depending on the method: $50 \mathrm{ppb} \div 1000 \mathrm{ppm}$,

- $\mathrm{pH}$ has been determined using the potentiometer method with $\mathrm{pH}$-metre, according to the PN-EN ISO 10523:2012 [21].

The paper presents the issue of using classic Fenton's reagent modification - sodium percarbonate $\left(2 \mathrm{Na}_{2} \mathrm{CO}_{3} \cdot 3 \mathrm{H}_{2} \mathrm{O}_{2}\right)$ was used as an alternative source of hydrogen peroxide, and hydrated iron sulphate ((II) $\mathrm{FeSO}_{4} \cdot 7 \mathrm{H}_{2} \mathrm{O}$ ) was the source of iron ions. The tests were carried out at initial process $\mathrm{pH}=3$ (adjustment with concentrated $\mathrm{H}_{2} \mathrm{SO}_{4}$ ) at the temperature $20^{\circ} \mathrm{C} \pm 1{ }^{\circ} \mathrm{C}$, for different doses of the $\mathrm{Fe}^{2+}$ catalyst (ranging within $100 \div 5400 \mathrm{mgFe} / \mathrm{L}$ ), and for mass ratio between iron (II) and sodium percarbonate - 1:3. After adding the reagents, leachates were mixed for $1 \mathrm{~min}$. at the rate of $100 \mathrm{rpm}$ and temperature $20^{\circ} \mathrm{C} \pm 1^{\circ} \mathrm{C}$. After $90 \mathrm{~min}$. of oxidation (mixing rate during reaction $50 \mathrm{rpm}$ ) in the Conbest JLT6 reactor, the samples were neutralised using $10 \% \mathrm{KOH}$ to $\mathrm{pH}=7.5$. Then, the leachates were mixed for $30 \mathrm{~min}$. at the rate of $10 \mathrm{rpm}$, and then were put to sedimentation for $30 \mathrm{~min}$. Three doses were selected after this stage, for which the following parameters were examined: the effect of initial process $\mathrm{pH}$ ranging between 2 and 4 (adjustment with concentrated $\mathrm{H}_{2} \mathrm{SO}_{4}$ ), the effect of oxidation process duration $(30 \div 150 \mathrm{~min}$. every $30 \mathrm{~min}$.), and the effect of the ratio $\mathrm{Fe}^{2+}$ to sodium percarbonate (1:3, 1:5 and 1:7).

\section{Test results and analysis}

Results obtained after leachate analysis are shown in Figs. 1-7. TOC of untreated effluent was $(854 \pm 10)$ $\mathrm{mgC} / \mathrm{L}$, while COD $(3832 \pm 10) \mathrm{mgO}_{2} / \mathrm{L}$, respectively. Initially, the tests included landfill leachate susceptibility to oxidation with the modified Fenton's method, using sodium percarbonate in place of hydrogen peroxide. The process was carried out at $\mathrm{pH}=3$. The results of $\mathrm{TOC}$ reduction for oxidiser dose range from 300 to 16200 $\mathrm{mg} / \mathrm{L}$ are shown in Fig. 1. The results of TOC value reduction were increasing with growing sodium percarbonate dose. Greatest changes were observed within range from 300 to $7200 \mathrm{mg} / \mathrm{L}$, and thus oxidiser dose $7200 \mathrm{mg} / \mathrm{L}$ was selected for further tests. 


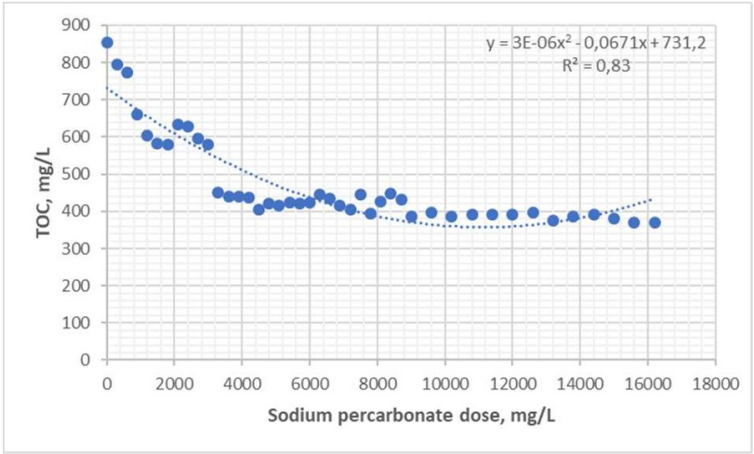

Fig. 1. The effect of sodium percarbonate dose on TOC value $\left(\mathrm{Fe}^{2+} / 2 \mathrm{Na}_{2} \mathrm{CO}_{3} \cdot 3 \mathrm{H}_{2} \mathrm{O}_{2}=0.33\right)$

After Fenton's process, it was possible to achieve ca. $53 \%$ TOC elimination efficiency for oxidiser dose $7200 \mathrm{mg} / \mathrm{L}$. For predetermined ratio $\mathrm{Fe}^{2+} / 2 \mathrm{Na}_{2} \mathrm{CO}_{3} \cdot 3 \mathrm{H}_{2} \mathrm{O}_{2}=0.33$, this corresponds to catalyst dose $2400 \mathrm{mgFe}^{2+} / \mathrm{L}$. Maximum efficiency of TOC value reduction has been obtained for oxidiser dose $15600 \mathrm{mg} / \mathrm{L}$ - 57\%, corresponding to TOC value - 369 $\mathrm{mgC} / \mathrm{L}$.

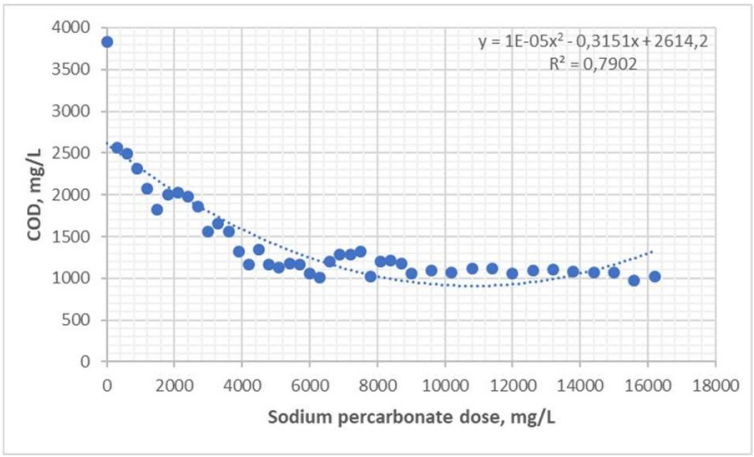

Fig. 2. The effect of sodium percarbonate dose on COD value $\left(\mathrm{Fe}^{2+} / 2 \mathrm{Na}_{2} \mathrm{CO}_{3} \cdot 3 \mathrm{H}_{2} \mathrm{O}_{2}=0.33\right)$

The results of COD value reduction for sodium percarbonate doses selected as above are shown in Fig. 2. Observed COD elimination efficiency was increasing for oxidiser dose range from 300 to 6300 $\mathrm{mg} / \mathrm{L}$, same as it was for TOC index, however COD value was reduced only to $1014 \mathrm{mg} / \mathrm{L}$. Reaching a threedigit value was possible just for oxidiser dose $15600 \mathrm{mg} / \mathrm{L}$. For ratio $\mathrm{Fe}^{2+} / 2 \mathrm{Na}_{2} \mathrm{CO}_{3} \cdot 3 \mathrm{H}_{2} \mathrm{O}_{2}=0.33$, this corresponds to catalyst dose $5200 \mathrm{mgFe}^{2+} / \mathrm{L}$. Applying so large reagent doses seems to be disputable from economic point of view. Moreover, the leachate decontamination effect is only slightly higher (Fig. 2). On the other hand, promising COD elimination efficiency reaching $74 \%$ was obtained already for oxidiser dose $6300 \mathrm{mg} / \mathrm{L}$. This value is almost $1 / 4$ higher than that obtained for TOC. Further tests were aimed to find the most advantageous value of ratio $\mathrm{Fe}^{2+} / 2 \mathrm{Na}_{2} \mathrm{CO}_{3} \cdot 3 \mathrm{H}_{2} \mathrm{O}_{2}, \mathrm{pH}$ and reaction time. The effect of $\mathrm{Fe}^{2+}$ ions share on TOC value reduction results was examined for three catalyst doses: $2400 \mathrm{mgFe}^{2+} / \mathrm{L}$, $3000 \mathrm{mgFe}^{2+} / \mathrm{L}$ and $4000 \mathrm{mgFe}^{2+} / \mathrm{L}$, respectively, for catalyst / oxidiser ratio ranging from $0.14 ; 0.2$ and 0.33 . Test results are shown in Figures 3 and 4.

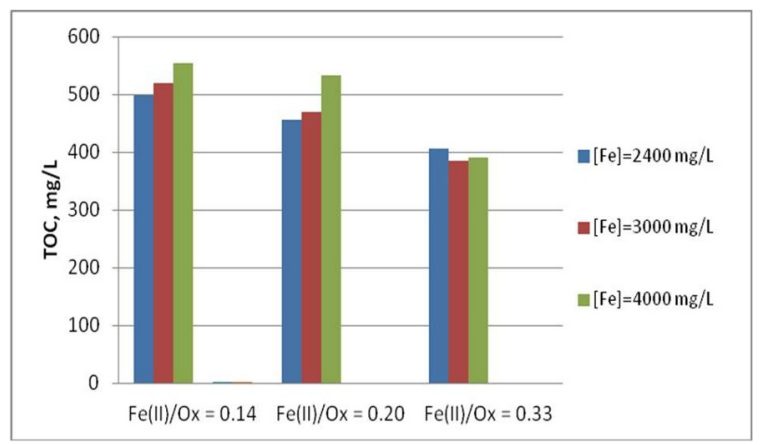

Fig. 3. The effect of the value of mass ratio $\mathrm{Fe}^{2+} / 2 \mathrm{Na}_{2} \mathrm{CO}_{3} \cdot 3 \mathrm{H}_{2} \mathrm{O}_{2}$ on TOC elimination efficiency

Results obtained at this stage of studies allow stating in an unambiguous way that maintaining the ratio catalyst / oxidiser at 0.33 gives optimal results for wide range of $\mathrm{Fe}^{2+}$ doses (Fig. 3; Fig. 4). The efficiency was growing most while increasing the value of $\mathrm{Fe}^{2+}$ / (sodium percarbonate) ratio from 0.20 to 0.33 . This results from the fact that ensuring high Fenton's process efficiency requires adequately high concentration of the $\mathrm{Fe}^{2+}$ ions. However, as proven by Barbusiński in $[16,17]$, too high concentration of $\mathrm{Fe}^{2+}$ ions may be the reason for reducing the concentration of hydroxyl radicals in the following reaction:

$$
\mathrm{Fe}^{2+}+{ }^{\cdot} \mathrm{OH} \rightarrow \mathrm{Fe}^{3+}+\mathrm{OH}^{-}
$$

However, on the other hand when the ratio catalyst/oxidiser is too low, the dose of iron (II) may be insufficient to produce the required number of hydroxyl radicals, as it is shown in general Fenton's reaction equation [17]. It is worth mentioning that precisely optimal concentration of ${ }^{\circ} \mathrm{OH}$ radicals is the main factor affecting efficiency of landfill leachate decontamination process.

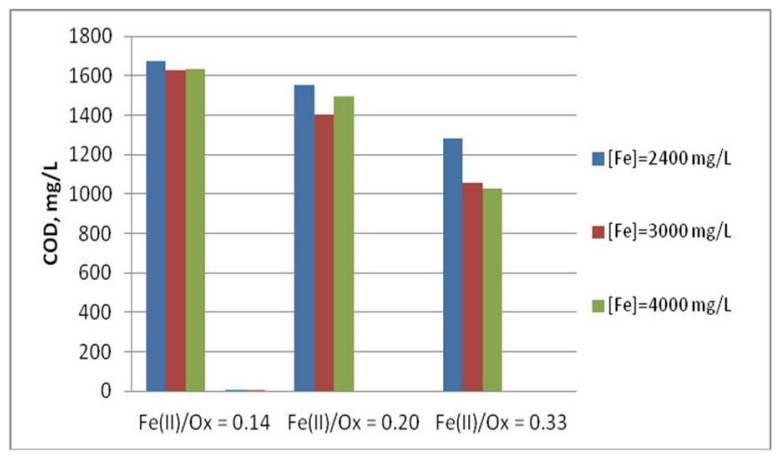

Fig. 4. The effect of the value of mass ratio $\mathrm{Fe}^{2+} / 2 \mathrm{Na}_{2} \mathrm{CO}_{3} \cdot 3 \mathrm{H}_{2} \mathrm{O}_{2}$ on COD elimination efficiency

The catalyst $/$ oxidiser ratio $=0.33$ has been chosen for further testing stages. The selection of the most favourable reaction $\mathrm{pH}$ and reaction time has been made for this proportion of iron (II) ions to sodium percarbonate. 


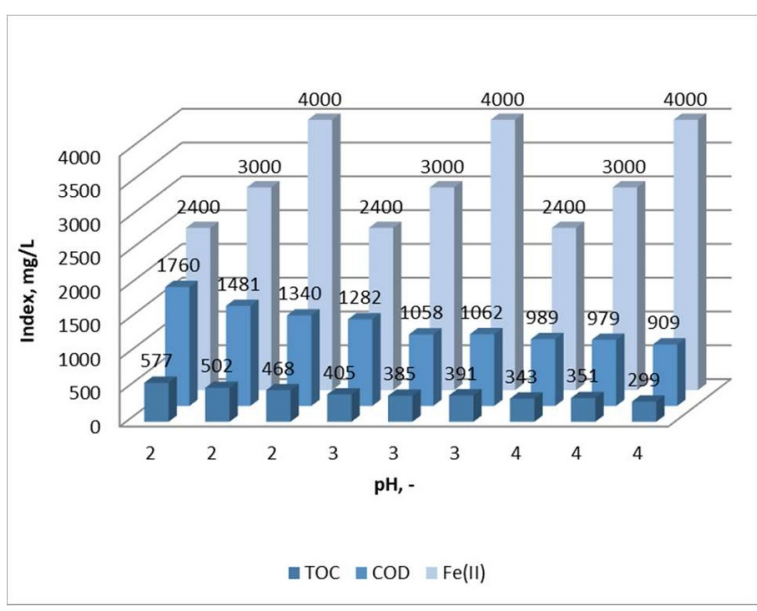

Fig. 5. The effect of $\mathrm{pH}$ on the efficiency of COD and TOC elimination from landfill leachates

Test results are shown in Fig. 5. In case of optimising $\mathrm{pH}$ value for the process involving landfill leachate remediation it is observed that the highest efficiency of the TOC and COD values elimination has been obtained for $\mathrm{pH}=4$ (Fig. 5). TOC value below $300 \mathrm{mgC} / \mathrm{L}$ has been obtained for catalyst dose $4000 \mathrm{mgFe} / \mathrm{L}$. It is equally interesting that at $\mathrm{pH}=4$, COD values obtained for leachates after Fenton's process have been evidently below the boundary of $1000 \mathrm{mgO}_{2} / \mathrm{L}$ for all three catalyst doses. The $\mathrm{pH}$ value reduction to 3 and 2 contributed to deteriorated decontamination effects, especially for $\mathrm{pH}=2$ (Fig. 5). This results from the fact that in case of higher concentration of oxonium ions $\mathrm{H}_{3} \mathrm{O}^{+}$, these ions may effectively compete with organic matter for primacy in the reaction with hydroxyl radicals:

$$
\mathrm{H}_{3} \mathrm{O}^{+}+{ }^{\cdot} \mathrm{OH} \rightarrow 2 \mathrm{H}_{2} \mathrm{O}+e^{-}
$$

advisability of using $\mathrm{pH}$ higher than 4 has not been confirmed at the testing stage. In this case, theoretical prerequisites indicate decreasing probability of producing the required number of ${ }^{\circ} \mathrm{OH}$ radicals.

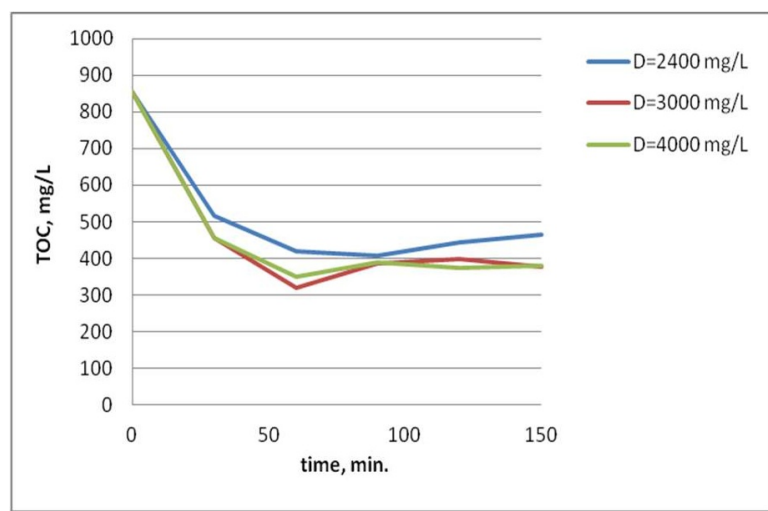

Fig. 6. The effect of reaction time on the efficiency of eliminating TOC from landfill leachates

The tests on the effect of landfill leachate decontamination process duration were carried out at preset catalyst doses: $2400 \mathrm{mg} / \mathrm{L}, 3000 \mathrm{mg} / \mathrm{L}$ and 4000 $\mathrm{mg} / \mathrm{L}$, predetermined catalyst / oxidiser ratio: 0.33 , and for reference $\mathrm{pH}$ value. It has been proven (Figs. 6, 7) that for all selected catalyst doses, the required reaction time should not be less than 60 minutes. Shorter time does not guarantee reaching required decontamination efficiency measured by the decrease in TOC (Fig. 6) and COD (Fig. 7). Increase in the reaction time over 60 minutes has no significant effect on the process efficiency, and it may just contribute to aggravated results of remediation in the economic aspect.

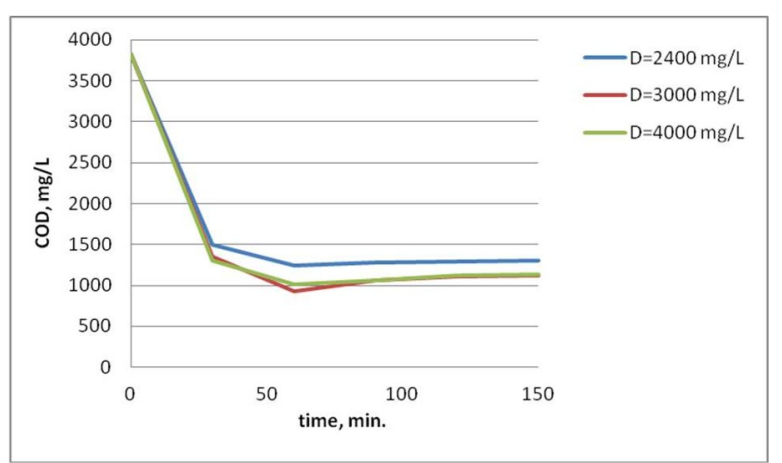

Fig. 7. The effect of reaction time on the efficiency of eliminating COD from landfill leachates

\section{Summary}

As a result of landfill functioning, pollution emissions are generated, which may pose hazard to environment, e.g. landfill leachates. Highly concentrated landfill leachates generated in this way require specialist treatment, and when choosing treatment technology, one should take into account i.a. changing chemical constitution of leachate, its volume, and capital intensity of the method. More and more often, the advanced oxidation methods, which include the Fenton's process, become an alternative for conventional treatment methods. Completed studies have proven that the employed implementation of Fenton's method with sodium percarbonate may be an effective alternative for hydrogen peroxide as an oxidiser. It has been proven that with increasing dose of $2 \mathrm{Na}_{2} \mathrm{CO}_{3} \cdot 3 \mathrm{H}_{2} \mathrm{O}_{2}$, the improvement in landfill leachate remediation efficiency measured by decreasing TOC and COD values reaches certain extent only. Optimal catalyst / oxidiser ratio of 0.33 has been determined. Best possible process duration of 60 minutes has been found. It has been proven that the process modified with sodium percarbonate may be effective already at $\mathrm{pH}=4$.

\section{Acknowledgements}

Publication supported by the Polish Ministry of Science and Higher Education as a part of the program of activities disseminating science from the project „Organization of the First International Science Conference - Ecological and Environmental Engineering”, 26-29 June 2018, Kraków. 


\section{References}

1. K. Frączek, H. Różycki, D. Ropek, Ecol. Chem. Eng. S, 21, 2 229-243 (2014)

2. I. Tałałaj, P. Biedka, M. Walery, J. Leszczyński, , JEE, 17, 3 175-184 (2016)

3. J. Koc-Jurczyk, Ł. Jurczyk, P. Micał, ENVIRON PROT ENG., 14, 1 59-71 (2011) (in Polish).

4. M. Czop, E. Kraus, ARCH ENVIRON PROT., 19, 1 31-38 (2017)

5. M. Dębicka, M. Żygadło, J. Latosińska, Open Chemistry, 15 67-74 (2017) doi: 10.1515/chem2017-0009.

6. B. Klojzy-Kaczmarczyk, J. Staszczak, GEOL SURV DEN GREENL, 63, 10/1 825-829 (2015) (in Polish).

7. J. Leszczyńsk, ENVIRON ENG SCI, 43 75-79 (2015) (in Polish)

8. S. Raghab, A. Abd El Meguid, H. Hegazi, HBRC, 9 187-192 (2013)

9. D. Kulikowska, Ecol. Chem. Eng. S, 16, 3 329-402 (2009) (in Polish)

10. P. Jelonek, E. Neczaj, IOS, 17, 3 493-502 (2014) (in Polish).

11. Ł. Jurczyk, J. Koc-Jurczyk, P. Różalska, IOS, 14, 4 309-322 (2011) (in Polish).
12. J. Leszczyński, ENVIRON ENG SCI, 40 17-24 (2014) doi: 10.12912/2081139X.65 (in Polish).

13. E. Wojciechowska, IOS, 17, 4 703-712 (2014) (in Polish).

14. P. Jelonek, E. Neczaj, IOS, 17, 3 493-502 (2014) (in Polish).

15. L. Dąbek, E. Ozimina, A. Picheta-Oleś, IOS, 14, 2 181-189 (2011) (in Polish)

16. K. Barbusiński, B. Pieczykolan, ACEE Journal, 4 93-100 (2010) (in Polish)

17. K. Barbusiński, PRZEM CHEM., 83, 6 285-290 (2004) (in Polish).

18. L. Dąbek, E. Ozimina, Ochr Środ i Zasob Natur., 41 369-376 (2009) (in Polish)

19. PN-ISO 5667-10:1997 Polish Standard. The quality of water - Collection of samples. Procedure guidelines concerning the collection of wastewater samples (in Polish)

20. PN-EN 1484:1999 Polish Standard. The quality of water - Water analysis - Water analysis guidelines for the determination of total organic carbon (TOC) and dissolved organic carbon (DOC) (in Polish)

21. PN-EN ISO 10523:2012 Polish Standard. The quality of water - Water analysis guidelines for the determination of $\mathrm{pH}$ 